\title{
Integrated study of 100 patients with Xp21 linked muscular dystrophy using clinical, genetic, immunochemical, and histopathological data. Part 2. Correlations within individual patients
}

\author{
Louise V B Nicholson, Margaret A Johnson, Kate M D Bushby, \\ David Gardner-Medwin, Ann Curtis, Ieke B Ginjaar, Johan T den Dunnen, \\ John L Welch, Tim J Butler, Egbert Bakker, Gert-Jan B van Ommen, John B Harris
}

Muscular Dystrophy Group Research Laboratories,

Regional

Neurosciences Centre, Newcastle General

Hospital, Newcastle upon Tyne NE4 6BE,

UK

L V B Nicholson

$M$ A Johnson

K M D Bushby

D Gardner-Medwin

J B Harris

Department of Human Genetics, University of

Newcastle upon Tyne NE2 4AA, UK.

A Curtis

Department of

Human Genetics,

Sylvius Laboratory,

2333 AL Leiden, The

Netherlands.

H B Ginjaar

$\mathrm{J} T$ den Dunnen

E Bakker

G-J B van Ommen

Department of Neuropsychology, Newcastle General Hospital NE4 6BE,

UK.

J L Welch

Department of Medical Statistics,

University of

Newcastle upon Tyne

NE2 4HH, UK.

T J Butler

Correspondence to

Dr Nicholson,

Neurochemistry

Department, Regional

Neurosciences Centre

Newcastle General Hospital,

Newcastle upon Tyne NE4

6BE, UK.

Received 22 February 1993

Revised version accepted

22 April 1993.

\section{Abstract}

This report is the second part of a trilogy from a multidisciplinary study which was undertaken to record the relationships between clinical severity and dystrophin gene and protein expression. The aim in part 2 was to correlate the effect of gene deletions on protein expression in individual patients with well defined clinical phenotypes. Among the DMD patients, most of the deletions/duplications disrupted the open reading frame, but three patients had in frame deletions. Some of the intermediate D/BMD patients had mutations which were frameshifting while others were in frame. All of the deletions/duplications in the BMD patients maintained the open reading frame and $25 / 26$ deletions in typical BMD group 5 started with exon 45 . The deletion of single exon 44 was the most common mutation in patients from groups 1 to 3. Dystrophin was detected in sections and blots from $58 \%$ of the DMD patients with a size that was compatible with synthesis from mRNA in which the reading frame had been restored. Certain deletions were particularly associated with the occurrence of limited dystrophin synthesis in DMD patients. For example, 9/11 DMD patients missing single exons had some detectable dystrophin labelling compared with $10 / 24$ who had deletions affecting more than one exon. All patients missing single exon 44 or 45 had some dystrophin. Deletions starting or finishing with exons 3 or 51 (8) 9) cases were usually associated with dystrophin synthesis whereas those starting or finishing with exons 46 or 52 (11/11) were not. Formal IQ assessments (verbal, performance, and full scores) were available for 47 patients. Mean IQ score among the DMD patients was 83 and no clear relationship was found between gene mutations and $I Q$. The mutations in patients with a particularly severe deficit of verbal IQ were spread throughout the gene.

(f Med Genet 1993;30:737-44)

Duchenne and Becker muscular dystrophy (DMD/BMD) are both caused by mutations in the dystrophin gene. ${ }^{1}$ A proposal was made, however, that the difference in protein expression and in clinical phenotype was caused by deletion breakpoints either disrupting (DMD) or maintaining (BMD) the open reading frame of nucleotide triplets or codons which determine the amino acid sequence. ${ }^{2}$ This 'frame shift hypothesis' predicts that Becker patients would produce a semifunctional protein of smaller size or molecular weight than normal, whereas in Duchenne patients the dystrophin protein would be absent owing to the rapid degradation of a severely truncated polypeptide which could only be synthesised up to the approximate position of the gene deletion before the frameshift generated a premature stop codon. Such truncated polypeptides would have no $\mathrm{C}$-terminus. ${ }^{3}$ The prediction that DMD patients have frameshifting deletions and BMD patients have deletions which keep the reading frame intact has proved to be correct in over $90 \%$ of the cases examined ${ }^{45}$ although certain exceptions (particularly involving BMD patients with the frameshifting deletion of exons 3 to 7) have been noted. ${ }^{6}$

In the preceding paper we considered the trends across the clinical spectrum in a cohort of 100 patients with $\mathrm{Xp} 21$ linked muscular dystrophy. In this paper our aim was to study the effects that gene deletions (or duplications) had on protein expression in individual patients with well defined clinical phenotypes. In part 3 we review what we have found in the context of differential diagnosis and prognosis.

\section{Materials and methods}

GENE AND PROTEIN ANALYSIS

The methods used are described in part 1 of this report. The effect of gene deletions on the reading frame was calculated from the data on exon border codon type $(1,2$, or 3$)$ provided by Koenig et $a l^{4}$ and Worton and Gillard. ${ }^{7}$ The size of the dystrophin protein present in muscle samples (the observed size) was estimated by comparing the blot migration distance of the uppermost band in each sample lane with the migration distance of the corresponding band in normal control muscle run on the same blot. ${ }^{8}$ The normal size was taken to be $427 \mathrm{kDa}$. The predicted size of the dystrophin protein produced by each patient was considered to be $427 \mathrm{kDa}$ if no gene deletion or duplication was detected. If a mutation was found, the predicted size was estimated from 
the effect the deletion or duplication was expected to have on the total number of amino acids present. For patients with 'in frame deletions' this was straightforward but the predicted size in patients with 'out of frame deletions' was calculated in two ways. ${ }^{8}$ Predicted size [A] was the size expected if translation was prematurely terminated at the stop codon generated by each frameshifting deletion (that is, estimated molecular mass of amino acids up to the breakpoint plus those up to the stop codon). This corresponds to the production of a truncated protein. Predicted size [B] was the size expected if the reading frame was immediately restored in the codon following the deletion breakpoint (calculated as for an in frame deletion). This corresponds to the production of an internally deleted or 'Becker-like' protein.

\section{IQ TESTS}

Formal assessments of IQ scores were made using the original and the revised forms of the Wechsler Intelligence Scale for Children (WISC, WISC-R). ${ }^{9}$ This widely used system of IQ appraisal contains a battery of individually administered tests with both verbal and non-verbal (performance) components. Eleven different subtests make up the WISC. Wechsler classified six of them as verbal (information, comprehension, arithmetic, similarities, vocabulary, and digit span), and five as performance subtests (coding, picture completion, picture arrangement, block design and object assembly). The WISC covers the age

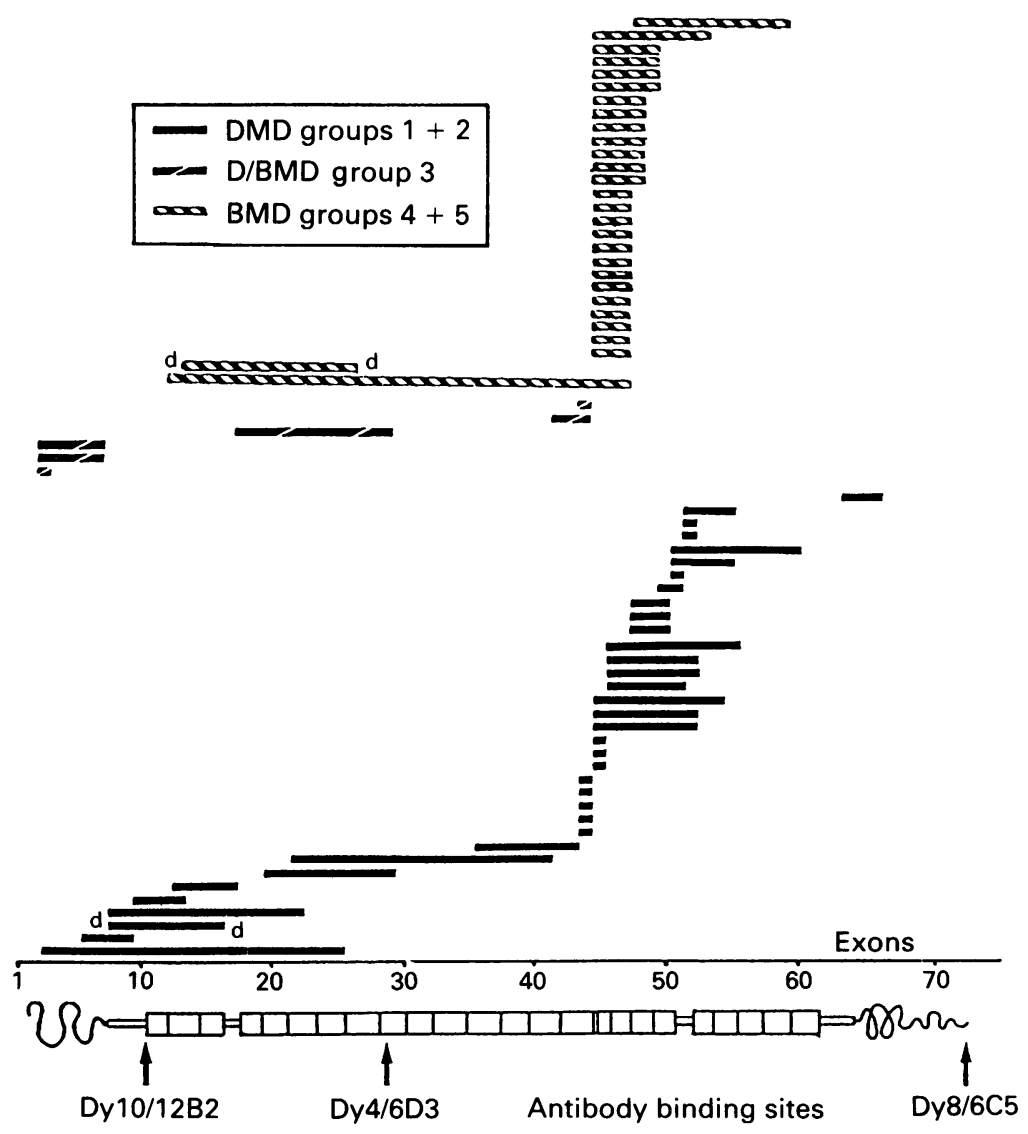

Figure 1 Exons deleted or duplicated (d) in patients old enough to be classified into clinical groups. The location of the binding sites of the antibodies used in this study, in relation to the exons and to a diagrammatic representation of the dystrophin molecule, is shown in the lower part of the figure. range from 5 to 15 years and the WISC-R from 6 to 16.9 years. Both the WISC and the WISC-R have been assessed on a sample of 2200 children and a mean score of 100 with a standard deviation of 15 IQ points have been established. A mean verbal performance discrepancy score of 0 with a standard deviation of 12.5 IQ points has been reported for this sample by Seashore et al. ${ }^{1011}$

\section{Results}

EFFECT OF GENE MUTATIONS ON THE READING FRAME

Of 62 mutations (deletions or duplications) where the effect on the reading frame and the clinical group of the patient could be ascertained, agreement with the 'reading frame hypothesis'12 was found in $100 \%(26 / 26)$ of BMD patients, and in $90 \%(27 / 30)$ of DMD patients (appendix in part 1 of the investigation). Three DMD patients from group 2 had in frame deletions. One of these (S39 in the appendix in part 1), who was missing exons 3 to 25 , produced dystrophin with Becker-like abundance and distribution, ${ }^{12}$ while protein expression in the other two (S43 and S46) was like that typically found in DMD patients. Deletions among individual intermediate $D$ / BMD patients in group 3 varied; some were in frame while others were out of frame. Two patients who had exons 3 to 7 deleted were in this clinical group.

\section{CLINICAL/GENETIC CORRELATIONS}

All deletions found in Becker patients from groups 4 and 5 spanned more than one exon. The mutations found in patients with the mildest clinical symptoms (group 5) were extremely consistent with $25 / 26$ deletions starting with exon 45 (fig 1). More severely affected BMD patients (group 4) had more unusual mutations, consisting of large duplications or substantial deletions within the central rod domain. Only patients with the most severe phenotypes (groups 1 to $3, \mathrm{DMD}$ or $\mathrm{D} / \mathrm{BMD}$ ) had mutations in the $5^{\prime}$ end of the gene or deletions of single exons. The frameshifting deletion of single exon 44 was the most common mutation found among DMD and D/ BMD patients. Furthermore, patients missing exon 44 were generally more mildly affected with DMD: these patients lost independent mobility at $9,10,10 \cdot 4,11,11 \cdot 3$, and 13.9 years compared with our DMD population mean of 9 years.

GENE MUTATIONS AND PROTEIN EXPRESSION Blots of muscle samples from patients with diverse clinical phenotypes are shown in fig 2 . In control muscle, a characteristic profile of dystrophin metabolites was normally present in blots labelled with the rod MAb. All the dystrophin bands were less intensely labelled with the C-terminal MAb (see part 1 of this investigation). Although the estimates of dystrophin size and abundance (summarised in the appendix in part 1) were calculated from 


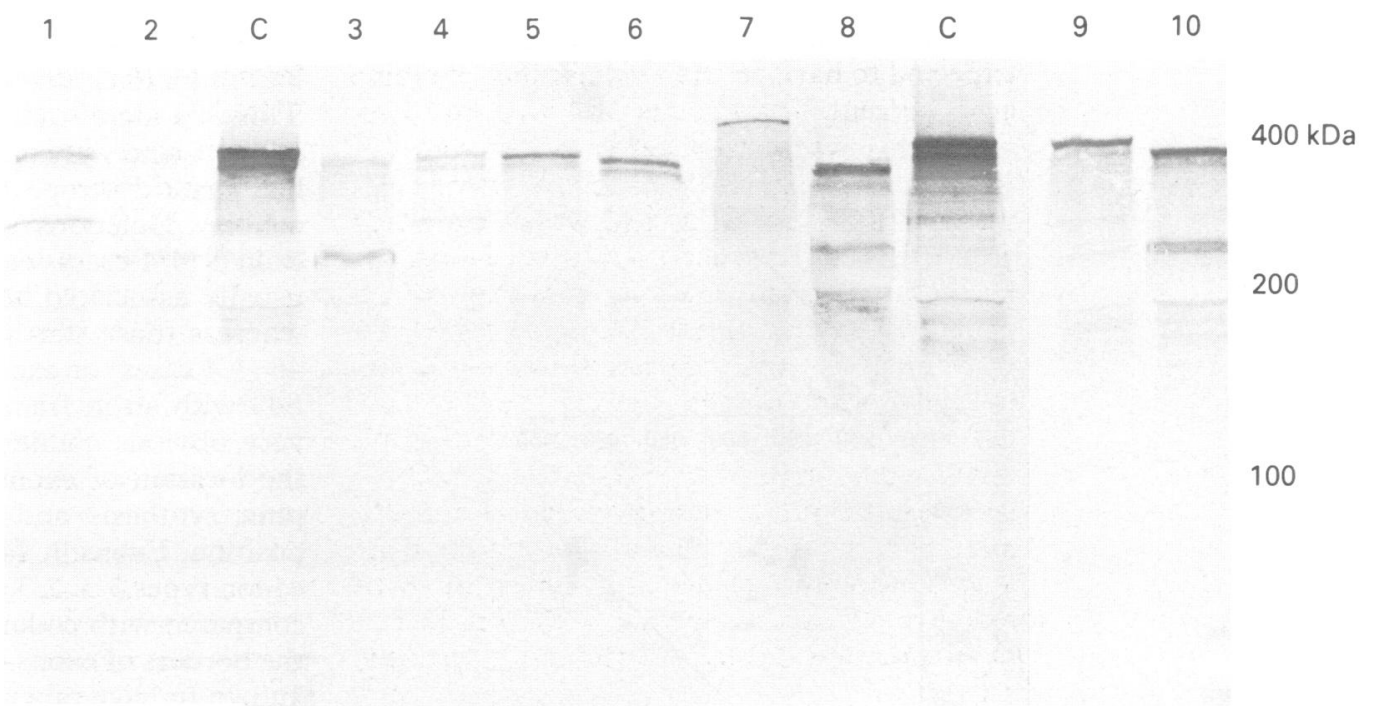

Rod domain
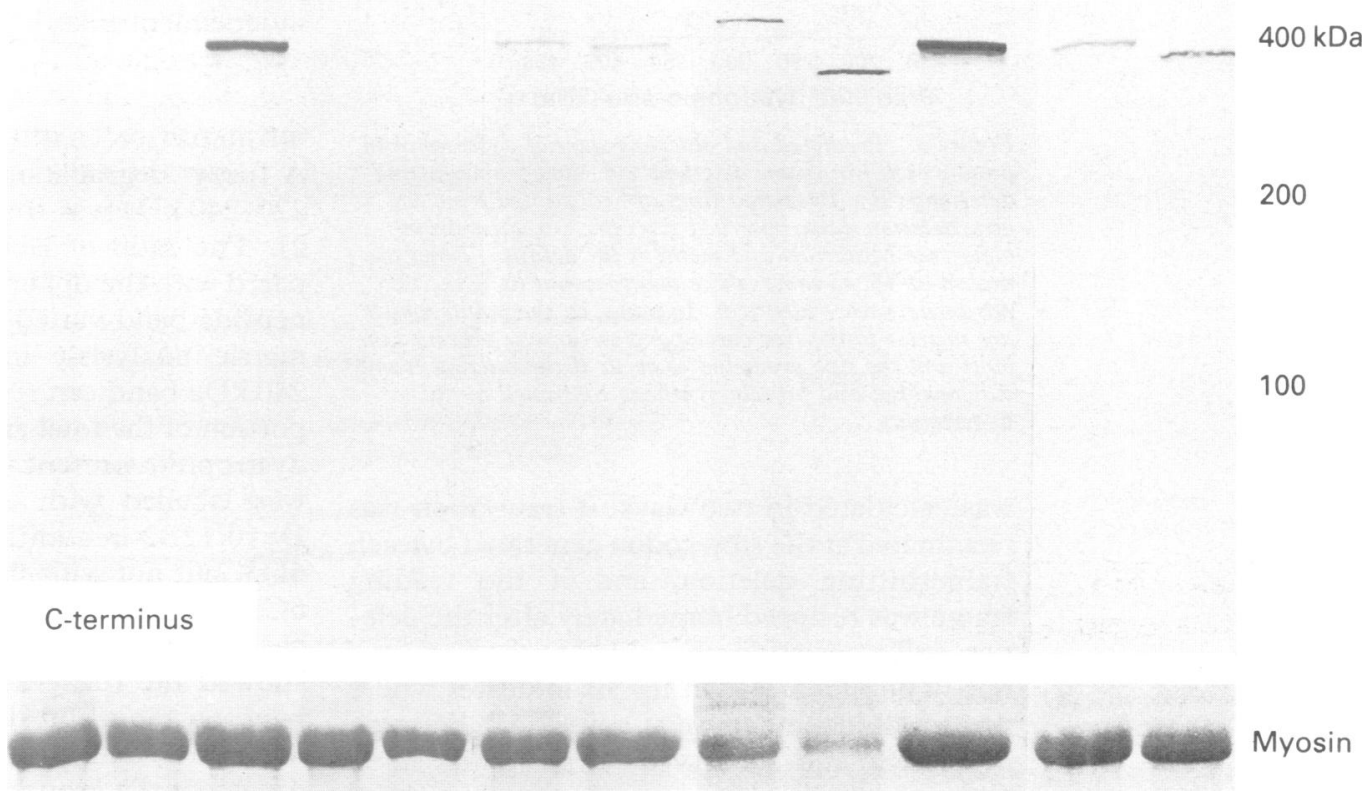

Myosin

Figure 2 Western blots of muscle from DMD patients (lanes 1 to 4), intermediate D/BMD patients (lanes 5 and 6), and BMD patients (lanes 7 to 10). Lanes with normal control muscle are labelled $C$. The upper panel shows labelling with the rod $M A b$ Dy4/6D3, and the lower panel shows aliquots from the same samples labelled with the $C$-terminal MAb Dy/6C5. Staining of the myosin heavy chain band from a corresponding gel (bottom of figure) is used as a measure of the muscle protein loaded in each lane. Lanes 1 to 10 are from patients B13, S35, F31, F29, S55, S54, F58, S81, S77, and F63 respectively. A fuzzy degradation band at approximately 220 to $240 \mathrm{kDa}$ can be seen in lanes 8 and 10 of the blot labelled with the rod MAb.

the uppermost band labelled in each sample lane, which corresponds to the largest polypeptide detected for each patient, some samples did show additional bands of lower size. These might well represent truncated translation products which were terminated prematurely. In this study no DMD patient was found who only produced truncated dystrophin, but occasional examples of this kind of labelling have been seen in our laboratory.

As expected, patients with in frame deletions produced vastly more dystrophin than patients with frameshifting deletions. Patients from the intermediate $D / B M D$ group 3 were interesting: of two group 3 patients with a very similar abundance of dystrophin, one (S55) had an in frame deletion of exon 3 (fig 2, lane 5) while the other (S54) had an out of frame deletion of exons 3 to 7 (fig 2, lane 6). The same value for dystrophin abundance was also found in two more group 3 patients with the in frame deletion of exons 42 to 44 (B49) and the frameshifting deletion of exon 44 (B50).

The observed size of any dystrophin protein in the biopsies was determined from the migration distance of bands on Western blots labelled with the rod MAb Dy4/6D3. The predicted size was estimated from the effect any mutation might have on the total number of amino acids synthesised. For patients with in frame deletions this was straightforward and fig $3 \mathrm{~A}$ shows that there is good agreement between the predicted and observed sizes in these cases. The situation with patients who had frameshifting deletions is more complicated. For these patients, the predicted size 


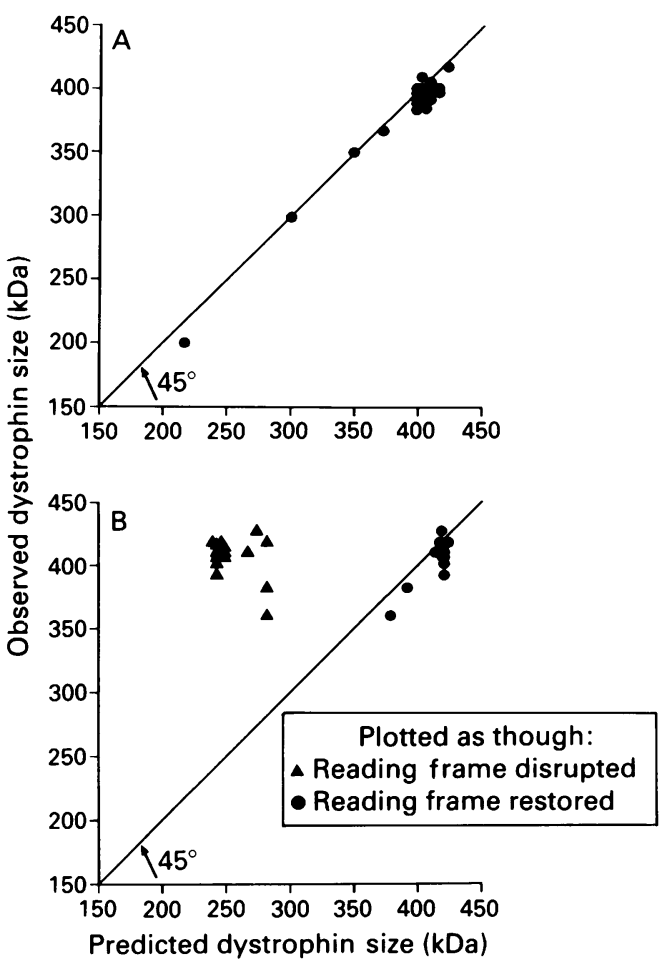

Figure 3 Predicted and observed sizes of dystrophin in patients with in frame deletions $(A)$ and frameshifting deletions $(B)$. Predicted sizes are calculated from the gene deletion data, observed sizes are estimated from blots (see Materials and methods for details). Lines are drawn at $45^{\circ}$ to show where points would lie if the two parameters were identical. In panel $B$, the points which are nearest to the line correspond to the size observed on blots and the size predicted to occur if the reading frame was restored and protein synthesis continued to the C-terminus.

was calculated in two ways: if translation was terminated at the stop codon generated by each frameshifting deletion, and if the reading frame was restored immediately after the deletion and translation proceeded to the C-terminus. The line at $45^{\circ}$ in fig $3 \mathrm{~B}$ indicates where there would be complete agreement between predicted and observed dystrophin sizes. Clearly, all the points which are plotted for predicted sizes with restored reading frame are much closer to this line. Thus, the size of dystrophin observed in patients with frameshifting deletions did not correspond to truncated polypeptides synthesised up to premature stop codons, but instead matched the sizes expected if the reading frame was restored and low levels of an internally deleted or 'Beckerlike' protein was synthesised through to the Cterminus.

MUTATIONS IN DMD PATIENTS WITH LOW LEVELS OF DYSTROPHIN

Sufficient dystrophin to estimate the polypeptide size was detected on blots from $24 / 41$ (58\%) DMD patients from groups 1 and 2 . Of these, 19 had detectable mutations and five had none. The exons that were deleted or duplicated in the DMD boys with detectable levels of dystrophin on blots were spread throughout the length of the molecule but certain types of deletion were more frequently associated with dystrophin labelling. For example, 9/11 DMD patients with deletions of single exons had some dystrophin, compared with $10 / 24$ who had mutations affecting more than one exon. This is a significant difference $(p<0.05)$. All patients who were missing single exon 44 or 45 had some dystrophin (10/10 in entire patient cohort). Deletions starting or finishing with exon 3 (4/4 cases) or exon 51 (4/5 cases) were usually associated with dystrophin synthesis, whereas those starting or finishing with exon 46 (4/4 cases) or exon 52 (7/7 cases, including S43 with an in frame deletion) were not. No very obvious connection was found between the location of exons associated with dystrophin synthesis and the exon border codon position. Exons 3, 44, 45, and 51 have border codon types $3 / 3,2 / 3,3 / 2$, and $1 / 3$ respectively, compared with codon types of $2 / 3$ and $3 / 1$ for the borders of exons 46 and 52 . Boys who were known to have inherited their mutations were just as likely to have low levels of dystrophin as those who were isolated cases. The detection of limited dystrophin labelling in DMD patients was associated with a longer period of independent mobility (see part 3 ).

'DEGRADATION' BAND AT 220-240 kDa

A fuzzy 'degradation' band at approximately $220-240 \mathrm{kDa}$ was frequently seen on blots (fig 2 ). The ratio of labelling in this band compared with the uppermost, or largest size polypeptide band varied from 0.5 to 1.3 (densitometric analysis), indicating that the 220$240 \mathrm{kDa}$ band can represent a substantial proportion of the total amount of immunoreactive dystrophin present. The $220-240 \mathrm{kDa}$ band was labelled with the amino domain $\mathrm{MAb}$ Dy 10/12B2 in addition to the rod MAb Dy4/ 6D3, but not with the C-terminal MAb Dy8/ $6 \mathrm{C} 5$. In this investigation we found a very clear relationship between samples which showed the fuzzy $220-240 \mathrm{kDa}$ 'degradation' band on blots and deletions with breakpoints in the P20 intron between exon 44 and exon 45. All of the group 5 BMD patients who had deletions starting with exon $45(25 / 25)$ showed this band. The one BMD patient with a deletion starting with exon 48 did not. The band could also be identified on the blot of muscle from the carrier daughter of a patient missing exons 45 to 48 . This fuzzy $220-240 \mathrm{kDa}$ band was also found among group 1 to 3 intermediate $\mathrm{D} / \mathrm{BMD}$ and $\mathrm{DMD}$ patients (fig 2). Most (9/10) had deletions with P20 breakpoints (exons 42 to 44 , single exon 44 or 45 ), but the band was also observed in one patient with a duplication of exons 42 to 43 . Three patients missing exon 45 who had some detectable dystrophin did not show the band.

\section{GENE MUTATIONS AND INTELLIGENCE}

Formal estimates of IQ were available for 33 DMD patients from groups 1 and 2 (see appendix in part 1 of this investigation). The mean value for full scale IQ was 83 points in these patients. A significant difference was found between the scores for performance IQ (mean $=87)$ and verbal IQ $($ mean $=80)$ within individual patients $(p<0.01)$. The difference 
was more than $20 \mathrm{IQ}$ points in four patients (S17, F8, S48, S38) who had verbal IQ scores which were $24,25,33$, and 34 points lower than performance IQ scores. The mutations were different in each of these cases (deletion of exons 46 to 52, 48 to 50, or 44, and duplication of exons 8 to 16 , respectively). One patient (S21), with a deletion of exon 45, had a verbal IQ which was 21 points higher than his performance IQ. Fig 4 shows the full scale IQ scores for individual patients plotted against the exons that they are missing. IQ scores for patients without deletions are shown as bars on the left of fig 4. No clear relationship was found between IQ and the occurrence, extent, or position of gene deletions. Of eight DMD patients who had a full scale IQ of below 70 and who would therefore be classified as mentally retarded, five were missing exon 52 . However, the IQ scores of another six patients without exon 52 ranged from 71 to 121 . IQ scores for seven intermediate $\mathrm{D} / \mathrm{BMD}$ patients and for six BMD patients indicated that these patients were mostly of below average intelligence, although none was actually retarded.

\section{Discussion}

\section{GENE MUTATIONS AND INTELLIGENCE}

Dystrophin is found in brain as well as muscle and expression of the dystrophin gene is controlled by different $5^{\prime}$ promoters in various cell types or tissues, the full length brain isoform having an alternative first exon. ${ }^{13-15}$ It is possible that defects in the dystrophin gene might affect brain function just as they affect muscle function, although removal of the brain promoter is compatible with normal intellect. ${ }^{16-18}$ The majority of our DMD patients were of below average intelligence and the mean full scale IQ in our cohort was 83. This is in accord with previous reviews, which suggest that the mean IQ for DMD patients is one standard deviation below that of an age matched popu-

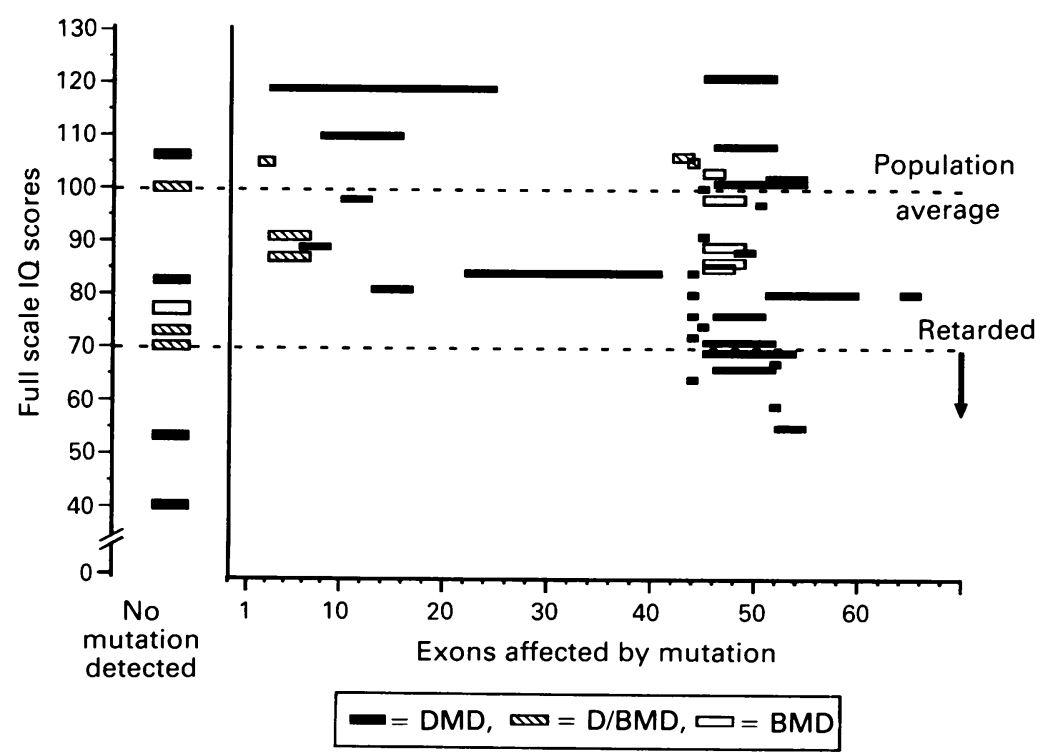

Figure 4 Position of mutations plotted against full scale (verbal and performance) $I Q$ scores. The extent of each bar on the horizontal axis indicates the exons which are affected in each patient. The vertical location of each bar indicates the $I Q$ score for that patient. An IQ score of 100 signifies average intelligence and any patient with an $I Q$ score below 70 is classified as retarded. lation of normal children. ${ }^{1920}$ Only $25 \%(8 / 32)$ had full scale IQ scores of below 70 and were considered mentally retarded. This compares with $50 \%(74 / 148)$ in a cohort of DMD patients in Brazil. ${ }^{21}$ Studying a group containing so many retarded patients enabled Rapaport $e t a l^{11}$ to find an association between the deletion of exon 52 and intellectual impairment: $70 \%(19 / 27)$ of patients missing this exon were mentally retarded and, conversely, $62 \%(24 / 39)$ of all retarded patients had deletions encompassing exon 52 . We found $5 / 11$ patients missing exon 52 were retarded and $5 / 8$ of retarded patients were without this exon. Both of our samples are too small for meaningful analysis. In agreement with Hodgson et $a l,{ }^{22}$ we found no retarded patients with deletions or duplications in the proximal half of the gene. No other obvious pattern emerged and patients with no detectable gene mutations had IQ scores in the same range as those with deletions. ${ }^{23}$ The mutations in patients with particularly low verbal scores compared with performance scores were spread throughout the gene. Normal subjects do not show the deficit in verbal IQ, ${ }^{11}$ which has been noted previously in DMD patients..$^{2024-26}$

Of particular note was one patient (S15) who had a deletion encompassing exons 64 to 66 . This would cause a defect in the recently identified brain isoform of dystrophin which is synthesised from an alternative transcript initiated between exons 62 and 63 of the full length mRNA. ${ }^{2728}$ Patient S15 was not remarkably retarded and had a full scale IQ of 80 which is close to our DMD mean of 83 .

Many of the DMD patients in this investigation had taken part in a previous study on head circumference and intellectual performance. ${ }^{29}$ In that study, the occipitofrontal head circumferences of $64 \mathrm{DMD}$ patients were measured and found to be greater than those of an age matched normal population: $47 / 64$ had relative macrocephaly and $12 / 64$ had absolute macrocephaly. No correlation was found between head circumference and intellectual performance. Preliminary data from unenhanced computerised tomography suggested that large heads were accompanied by an increase in brain size. ${ }^{29}$ The role, if any, of dystrophin gene products in the abnormal brain development is currently unknown.

\section{GENOTYPE/PHENOTYPE RELATIONSHIPS IN BMD}

Among the male patients, the strongest correlation between genotype and clinical phenotype was in group 5 patients with 'typical' BMD. All these patients had a mild clinical profile as indicated by muscle function tests (low Cornelio score for age).$^{30}$ The mutations associated with this clinical profile were clustered in a very small region, deletion of exons 45 to 47,45 to 48,45 to 49,45 to 53 accounting for $96 \%$ of the deletions detected. This is in agreement with previous studies. ${ }^{4531}$ Exactly why so many deletions start with exon 45 is uncertain. The position of DMD/BMD deletion breakpoints within the P20 intron preceding exon 45 are widely spaced. ${ }^{32}{ }^{33}$ Neither A-T 
rich sequences ${ }^{33}$ nor a transposon-like element, as reported within preceding intron $43,{ }^{34}$ seem to be general features of deletion breakpoints.

Group 5 patients had dystrophin labelling which was detectable in high abundance with both rod and C-terminal MAbs. The predominant feature of labelling on sections was variation, both between and within fibres but few examples of complete gaps (discontinuous labelling) were found which could not be directly related to histological or to artefactual changes. ${ }^{35}$ The profile of bands observed on blots included an uppermost band which was lower than normal (size appropriate for the in frame removal of amino acids) and included a fuzzy $220-240 \mathrm{kDa}$ degradation band for all patients with a deletion starting with exon 45 . This band has been noted previously on many occasions, ${ }^{36-42}$ and may represent unstable truncated polypeptides which have been synthesised up to the deletion breakpoint. In contrast to Beggs et al, ${ }^{43}$ we did not detect the band in a patient with a deletion starting in exon 48 , and we have no evidence that this band is associated with dystrophin degradation after removal of the biopsy. The band was detected in the obligate carrier daughter of a BMD patient missing exons 45 to 48 . All of the group 5 patients with no detectable mutation had dystrophin of a size which was indistinguishable from that in normal control muscle. This contrasts with Beggs et al $l^{44}$ who reported dystrophin of reduced size with no detectable gene deletion in five BMD patients.

Compared with the number of 'typical' BMD patients in northern England, there were relatively few patients with severe BMD. ${ }^{30}$ Group 4 severe BMD patients were found to have more heterogeneous mutations than their group 5 counterparts and all started on the $5^{\prime}$ side of exon 45 . Of particular note was patient $S 60$ who had an in frame deletion of exons 13 to 47 . The clinical phenotype of this patient was quite severe, and he became confined to a wheelchair at 17 years. Abundant dystrophin was found to be correctly localised at the periphery of muscle fibres. Published clinical details are available for very few cases with large in frame deletions like this. In one family, where exons 14 to 44 are missing, moderate disease progression was indicated by the requirement of a wheelchair at 44 years. ${ }^{45}$ Another example, where exons 17 to 48 were missing, ${ }^{46}$ was associated with such a mild phenotype (walking with the aid of a stick at 61 years) that the 'minigene' present in this family has been taken as a successful model for gene replacement therapy. ${ }^{47-50}$ From these very few patients one might predict that the clinical phenotype deteriorates as more exons are deleted proximal to exon 17. Analysis of the amino acids in exons 13 to 17 indicates that the triple helical repeats of the rod domain may be interrupted at this point, ${ }^{51}$ and sequences of particular conformational importance may reside here. It has been suggested that a hinge structure is located in exon $17,,^{52}$ but the absence of this exon in the mildly affected patient of England et al ${ }^{46}$ suggests that this may not be the case.
INTERMEDIATE D/BMD:THE PIVOTAL STAGE

There is a relatively small, but significant group of patients who do not fall within the classical definitions of either Duchenne or Becker muscular dystrophy. These patients, who have been called 'outliers', ${ }^{53}$ often present later than typical DMD patients (sometimes 8 years or later), and are wheelchair bound by 16 years. Respiratory function is often better maintained in this group than in typical DMD patients. Although small in number, these patients are particularly interesting because we need to fit their characteristics into the tenet of 'in frame BMD, out of frame DMD' and for a black and white reading frame it is difficult to generate the required shade of grey!

In this study, the deletions found in group 3 intermediate patients were proximal and distal, both in frame and out of frame, with both types generating dystrophin of similar intermediate abundance. The fact that intermediate D/BMD patients produced dystrophin at levels which were part way between BMD and DMD has been recognised from the start of the 'dystrophin era' ${ }^{36}$ How might this have been achieved? The exons that we found deleted in our group 3 patients $(3$ to 7,44$)$ are those that have been previously reported in association with both variable clinical phenotype $e^{4-654-56}$ and with exon skipping. ${ }^{5758}$ If deletions that were inherently in frame were being moved out of frame in a proportion of muscle transcripts and those that were inherently frameshifting were being brought back in to frame, the result might be protein synthesis which had varying characteristics intermediate between that found in DMD or BMD. The size of the dystrophin protein produced in patients with frameshifting deletions is compatible with restoration of the reading frame. Removing, or skipping, an additional exon (or exons) on one side or the other of a basic deletion has been shown to modify the effect that the original deletion had on the reading frame in a number of individual cases, ${ }^{5758}$ and it is possible that the phenomenon of exon skipping is more common than originally thought. Variation in the efficiency with which the reading frame is altered in transcripts within the muscle of individual patients could be one factor in the generation of family members with discordant clinical phenotypes. In this study one patient (B50) deleted for exon 44 is still just managing to walk in callipers at 25 years while his younger brother (not biopsied) was in a wheelchair at 8 years and died at 18 years.

\section{'RESCUE' OF DYSTROPHIN SYNTHESIS IN DMD} Mutations in the DMD groups 1 and 2 spanned the gene, with $90 \%$ producing a shift in the reading frame. Dystrophin was detected on tissue sections labelled with amino domain, rod domain, or C-terminal MAbs in $58 \%$ of the DMD patients. On blots labelled with the rod $M A b$, the size of the dystrophin molecules observed was consistent with the prediction of reading frame restoration (leading to internal deletion) rather than premature chain termina- 
tion (leading to simple truncation), a result compatible with the C-terminal labelling which was detected on sections. ${ }^{8}$ DMD biopsies which showed the most abundant dystrophin labelling frequently showed two distinct types of labelling on tissue section: clear labelling on a small percentage of fibres $(<1 \%)$ and very weak labelling on a much higher proportion $(<30 \%){ }^{3859}$ This suggests that there may be at least two different mechanisms involved in the restoration of the reading frame. One may occur at the nuclear level causing small isolated clones of dystrophin positive fibres, the other may be at transcript level causing barely detectable levels of dystrophin in large numbers of fibres.

Several mechanisms have been considered for altering the properties of myonuclei in dystrophin deficient muscle and, of these, somatic reversion or suppression are considered to be the most likely. ${ }^{6061}$ Somatic reversion to produce an internally deleted or 'Becker-like' protein in the DMD muscle could be caused by secondary deletions which restore the reading frame by either extending or removing the original mutation. Using panels of antibodies to different regions, Klein et $a l^{61}$ showed direct evidence for this in two DMD patients with no detectable deletions, and Wallgren-Pettersson et $a l^{62}$ found similar evidence in a DMD patient with exons 35 to 43 deleted in lymphocyte DNA. Somatic mosaicism is not considered plausible as a generalised mechanism, ${ }^{61}$ but it is certainly possible for the patient S56 in this study, whose biopsy contained one whole fascicle of fibres with very clear labelling and who has no family history of Xp21 muscular dystrophy. The association of particular DMD deletions with restored dystrophin synthesis that we observed suggests that certain deletions are more easily circumvented than others. This is supported by recent data on the varying incidence of 'revertant' fibres in new mutant strains of $m d x$ mice with different gene defects. ${ }^{63}$

Restoration of the reading frame at transcript level could be caused by illegitimate splicing or exon skipping as discussed for intermediate $\mathrm{D} / \mathrm{BMD}$ patients above, and studies of muscle mRNA from a small number of the DMD patients in this study are currently in progress. It is noteworthy that the incidence of weak labelling on many fibres increases from group 1 to group 3 just as the estimates of dystrophin abundance on blots increase. This suggests that low levels of dystrophin in a high proportion of fibres are likely to have more functional significance than higher levels in a very small number.

In summary, we found that the effect that deletion breakpoints have on the open reading frame is the one factor which exerts most influence on clinical phenotype. We would like to suggest, however, that this may be a simplification and that exon skipping or other forms of abnormal splicing could play a vital role in modifying the underlying defects in gene and protein expression in many DMD and intermediate $\mathrm{D} / \mathrm{BMD}$ patients. This would result in a spectrum of dystrophin synthesis being created. This spectrum is reflected in the disease severity which is observed in these patients, and may explain the existence of discordant clinical phenotypes in the same families.

The 100 patients in this study cover a very broad range of disease severity and in the third part of this report we use the data that we have collated in parts 1 and 2 to consider which factors or techniques were most informative, and therefore which would be most useful, for future differential diagnosis and prognosis.

This study relied for a large part on the technical expertise of Keith Davison, Martin Barron, Liz O'Donnell, Gavin Falkous, Daisy Haggerty, and Marleen van Paassen for which we are extremely grateful. The financial support of the University of Newcastle upon Tyne Research Committee, the Muscular Dystrophy Group of Great Britain, the Wellcome Trust, the Medical Research Council, the Association Française contre les Myopathies (AFM), the Princess Beatrix Fund, the Dutch Prevention Fund, and The Netherlands Foundation of Medical Research (MEDGON) is gratefully acknowledged.

1 Hoffman EP, Brown RH, Kunkel LM. Dystrophin: the protein product of the Duchenne muscular dystrophy locus. Cell 1987;51:919-28.

2 Monaco AP, Bertelson CJ, Liechti-Gallati S, Moser $\mathrm{H}_{\text {, }}$ Kunkel LM. An explanation for the phenotypic differences between patients bearing partial deletions of the DMD locus. Genomics 1988;2:90-5.

3 Hoffman EP, Kunkel LM. Dystrophin abnormalities in Duchenne/Becker muscular dystrophy. Neuron 1989;2:1019-29.

4 Koenig M, Beggs AH, Moyer M, et al. The molecular basis for Duchenne versus Becker muscular dystrophy: correlation of severity with type of deletion. Am $\mathcal{F}$ Hum Genet 1989;45:498-506.

5 den Dunnen JT, Grootscholten PM, Bakker E, et al. Topography of the Duchenne muscular dystrophy (DMD) gene: FIGE and CDNA analysis of 194 cases reveals 115 deletions and 13 duplications. Am 7 Hum Genet 1989;45:835-47.

6 Malhotra SB, Hart KA, Klamut HJ, et al. Frame-shift deletions in patients with Duchenne and Becker muscular dystrophy. Science 1988;242:755-9.

7 Worton RG, Gillard EF. Muscular dystrophy, molecular genetics. In: Encyclopedia of human biology. Vol 5. New genetics. In: Encyclopedia of human biol

8 Nicholson LVB, Bushby KMD, Johnson MA, et al. Predicted and observed sizes of dystrophin in some patients with gene deletions that disrupt the open reading frame. $\mathcal{f}$ Med Genet 1992;29:892-6.

9 Wechsler D. Manual for the Wechsler Intelligence Scale for Children - Revised. New York: The Psychological Corporation, 1974.

10 Seashore HG, Wesman A, Doppelt J. The standardisation of the Wechsler Intelligence Scale for Children. $\mathcal{F}$ Consult Psychol 1950;14:99-100.

11 Seashore HG. Differences between verbal and performance IQs on the Wechsler Intelligence Scale for Children. $\mathcal{F}$ Consult Psychol 1951;15:62-7.

12 Nicholson LVB, Bushby KMD, Johnson MA, GardnerMedwin D, Ginjaar HB. Dystrophin expression in Duchenne patients with 'in frame' gene deletions. NeuroDuchenne patients with

13 Nudel U, Zuk D, Einat P, et al. Duchenne muscular dystrophy gene product is not identical in muscle and brain. Nature 1989;337:76-8.

14 Chelly J, Hamard G, Koulakoff A, et al. Dystrophin gene transcribed from different promoters in neuronal and glial cells. Nature 1990;344:64-5.

15 Barnea E, Zuk D, Simantov R, Nudel U, Yaffe D. Specificity of expression of the muscle and brain dystrophin gene promoters in muscle and brain cells. Neuron 1990;5:8818.

16 den Dunnen JT, Casula L, Kakover A, et al. Mapping of dystrophin brain promoter: a deletion of this region is compatible with normal intellect. Neuromusc Dis 1991;1:327-31.

17 Boyce FM, Beggs AH, Feener CA, Kunkel LM. Dystrophin is transcribed in brain from a distant upstream promoter. Proc Natl Acad Sci USA 1991;88:1276-80.

18 Rapaport D, Passos-Bueno MR, Takata RI, et al. A deletion including the brain promoter of the Duchenne muscular including the brain promoter of the Duchenne muscular
dystrophy gene is not associated with mental retardation. Neuromusc Dis 1992;2:117-20.

19 Walton JN, Gardner-Medwin D. The muscular dystro- 
phies. In: Walton JN, ed. Disorders of voluntary muscle. Edinburgh: Churchill Livingstone, 1988:519-68.

20 Emery AEH. Duchenne muscular dystrophy. Revised edition. Oxford: Oxford University Press, 1988

21 Rapaport D, Passos-Bueno MR, Brandao L, et al. Apparent association of mental retardation and specific patterns of deletions screened with probes Cf56a and Cf23a in Duchenne muscular dystrophy $A m, \mathcal{M}$ d 1991;39:437-41.

22 Hodgson SV, Abbs S, Clark S, et al. Correlation of clinical and deletion data in Duchenne and Becker muscular dystrophy, with special reference to mental ability. dystrophy, with special refe

23 Bushby KMD, Appleton RE, Nicholson LVB, et al. Deleion status and intellectual impairment in Duchenne muscular dystrophy. Arch Dis Child (in press).

24 Karagan NJ, Richman LC, Sorensen JP. Analysis of verba disability in Duchenne muscular dystrophy. $\mathcal{F}$ Nerv Men Dis 1980;168:419-23.

25 Leibowitz D, Dubowitz V. Intellect and behaviour in Duchenne muscular dystrophy. Dev Med Child Neurol 1981;23:577-90.

26 Kaplan IC, Osborn P, Elias E. The diagnosis of muscular dystrophy in patients referred for language delay. $\mathcal{f}$ Child Psychol Psychiatry 1986;27:545-9.

27 Lederfein D, Levy Z, Augier N, et al. A $71 \mathrm{kd}$ protein is a major product of the Duchenne muscular dystrophy gene USA 1992;89:5346-50.

28 Hugnot JP, Gilgenkrantz H, Vincent N, et al. Novel products of the dystrophin gene: a distal transcript initiated from a unique alternative first exon encoding a $75 \mathrm{kD}$ protein widely distributed in non-muscle tissues. Proc Natl Acad Sci USA 1992;89:7508-10.

29 Appleton RE, Bushby KMD, Gardner-Medwin D, Welch JL, Kelly PJ. Head circumference and intellectual performance of patients with Duchenne muscular dystrophy. Dev Med Child Neurol 1991;33:884-90.

30 Bushby KMD, Gardner-Medwin D. The clinical, genetic and dystrophin characteristics of Becker muscular dystrophy. I. Natural history. $\mathcal{F}$ Neurol 1993;240:98-104.

31 Norman AM, Thomas NST, Kingston HM, Harper PS Becker muscular dystrophy: correlation of deletion type with clinical severity. $\mathcal{F}$ Med Genet 1990;27:236-9.

32 Blonden LAJ, den Dunnen JT, van Paassen HMB, et al. High resolution deletion breakpoint mapping in the
DMD gene by whole cosmid hybridization. Nucleic Acids DMD gene by whole

33 Love DR, England SB, Speer A, et al. Sequences of junctional fragments in the deletion-prone region of the dystrophin gene. Genomics 1991;10:57-67.

34 Pizzuti A, Pieretti M, Fenwick RG, Gibbs RA, Caskey CT A transposon-like element in the deletion-prone region of the dystrophin gene. Genomics 1992;13:594-600.

35 Slater CR, Nicholson LVB. Is dystrophin labelling always discontinuous in Becker muscular dystrophy? $\mathcal{f}$ Neurol Sci 1991;101:187-92.

36 Hoffman EP, Fischbeck KH, Brown RH, et al. Characterization of dystrophin in muscle-biopsy specimens from patients with Duchenne's or Becker's muscular dystrophy. $N$ Engl f Med 1988;318:1363-8.

37 Hoffman EP, Kunkel LM, Angelini C, et al. Improved diagnosis of Becker muscular dystrophy by dystrophin diagnosis of Becker muscular dyst

38 Nicholson LVB, Johnson MA, Gardner-Medwin D, Bhattacharya S, Harris JB. Heterogeneity of dystrophin expression in patients with Duchenne and Becker muscular dystrophy. Acta Neuropathol 1990;80:239-50.

39 Voit T, Stuettgen P, Cremer M, Goebel HH. Dystrophin as a diagnostic marker in Duchenne and Becker muscular dystrophy. Correlation of immunofluorescence and Western blot. Neuropediatrics 1991;22:152-62.

40 Bulman DE, Murphy EG, Zubrzycka-Gaarn EE, Worton RG, Ray PN. Differentiation of Duchenne and Becker muscular dystrophy phenotypes with amino- and carboxy-terminal antisera specific for dystrophin. Am $\mathcal{F}$ Hum Genet 1991;48:295-304.

41 Bushby KMD, Gardner-Medwin D, Nicholson LVB, et al. The clinical, genetic and dystrophin characteristics of Becker muscular dystrophy. II. Correlation of phenotype with genetic and protein abnormalities. $f$ Neurol with genetic and

42 Vainzof M, Passos Bueno MR, Rapaport D, Pavanello
RCM, Zatz M. Additional dystrophin fragment in Becker muscular dystrophy patients: correlation with the pattern of DNA deletion. Am $\mathcal{F}$ Med Genet 1992;44:382-4.

43 Beggs AH, Hoffman EP, Kunkel LM. Additional dystrophin fragment in Becker muscular dystrophy may result from proteolytic cleavage at deletion junctions. $A m \mathcal{F} \mathrm{Med}$ Genet 1992:44:378-81.

44 Beggs AH, Hoffman EP, Snyder JR, et al. Exploring the molecular basis for variability among patients with Becker muscular dystrophy: dystrophin gene and protein studies. Am f Hum Genet 1991;49:54-67.

45 Love DR, Flint TJ, Genet SA, Middleton-Price HR, Davies KE. Becker muscular dystrophy patient with a large intragenic dystrophin deletion: implications for functional minigenes and gene therapy. $f$ Med Genet 1991;28:860-4.

46 England S, Nicholson LVB, Johnson MA, et al. Very mild muscular dystrophy associated with the deletion of $46 \%$ of dystrophin. Nature 1990;343:180-2.

47 Acsadi G, Dickson G, Love DR, et al. Human dystrophin expression in $m d x$ mice after intramuscular injection of DNA constructs. Nature 1991;352:815-8.

48 Dickson G, Love DR, Davies KE, et al. Human dystrophin gene transfer: production and expression of a functional recombinant DNA-based gene. Hum Genet 1991;88:53-8.

49 Dunckley MG, Love DR, Davies KE, et al. Retroviral mediated transfer of a dystrophin minigene into $m d x$ mouse myoblasts in vitro. FEBS Lett 1992;296:128-34.

50 Wells DJ, Wells KE, Walsh FS, et al. Human dystrophin expression corrects the myopathic phenotype in transgenic $m d x$ mice. Hum Mol Genet 1992;1:35-40.

51 Koenig M, Monaco AP, Kunkel LM. The complete sequence of dystrophin predicts a rod-shaped cytoskeletal protein. Cell 1988;53:219-28.

52 Koenig M, Kunkel LM. Detailed analysis of the repeat domain of dystrophin reveals four potential hinge seg-
ments that may confer flexibility. $f$ Biol Chem ments that may

53 Brooke MH, Fenichel GM, Griggs RC, et al. Clinical investigation in Duchenne dystrophy. 2. Determination of the 'power' of therapeutic trials based on the natural history. Muscle Nerve 1983;6:91-103.

54 Medori R, Brooke MH, Waterston RH. Genetic abnormalities in Duchenne and Becker dystrophies: clinical correlations. Neurology 1989;39:461-5.

55 Baumbach LL, Chamberlain JS, Ward PA, Farwell NJ, Caskey CT. Molecular and clinical correlations of deletions leading to Duchenne and Becker muscular dystrophies. Neurology 1989;39:465-74.

56 Hodgson S, Hart K, Abbs S, et al. Correlation of clinical and deletion data in Duchenne and Becker muscular dystrophy. F Med Genet 1989;26:682-93.

57 Chelly J, Gilgenkrantz $\mathrm{H}$, Lambert $M$, et al. Effect of dystrophin gene deletions on mRNA levels and processing in Duchenne and Becker muscular dystrophies. Cell 1990;63:1239-48.

58 Roberts RG, Barby TFM, Manners E, Bobrow M, Bentley DR. Direct detection of dystrophin gene rearrangements by analysis of dystrophin mRNA in peripheral blood lymphocytes. Am F Hum Genet 1991;49:298-310.

59 Nicholson LVB, Johnson MA, Bushby KMD, GardnerMedwin D. The functional significance of dystrophinpositive fibres in Duchenne muscular dystrophy. Arch Dis Child 1993;68:632-6.

60 Hoffman EP, Morgan JE, Watkins SC, Partridge TA. Somatic reversion/suppression of the mouse $m d x$ phenotype in vivo. F Neurol Sci 1990;99:9-25.

61 Klein CJ, Coovert DD, Bulman DE, et al Somatic reversion/suppression in Duchenne muscular distrophy (DMD): evidence supporting a frame-restoring mechanism in rare dystrophin-positive fibres. Am $\mathcal{F}$ Hum Genet 1992;50:950-9.

62 Wallgren-Pettersson C, Jasani B, Rosser LG, et al. Immunohistological evidence for second or somatic mutation as the underlying cause of dystrophin expression by isolated fibres in Xp21 muscular dystrophy of Duchenneisolated fibres in $\mathrm{Xp} 21$

63 Gangopadhyay SB, Sherratt TG, Heckmatt JZ, et al. Dystrophin in frameshift deletion patients with Becker muscular dystrophy. Am $\mathcal{f}$ Hum Genet 1992;51:562-70. 